\title{
NATURE LIBRARY
}

\section{A BIRD-FINDING GUIDE TO CANADA}

Edited by J.C.FINLAY. 1984. Hurtig Publishers Ltd., Edmonton, Alberta. 387 pp., 13 maps, 40 b/w illus., 2 appendices. Soft Cover $\$ 18.95$. hardcover $\$ 27.95$.

Canada finally has its first national guide to bird finding. Covering every region of the country, from 5 to 22 major birding areas are described for each province and territory: for the prairies, 12 areas in Saskatchewan, 18 in Alberta and 14 in Manitoba. Cam Finlay has relied on knowledgeable birders from every region to select the best areas and to write the accounts. The result is an authoritative guide which can help you plan trips to visit a new birding spot, be it near home or farther afield to Last Mountain Lake, Churchill, Point Pelee, Montreal, Sable Island, Tuktoyaktuk or the coastal and offshore waters of British Columbia and the maritimes. It can also help you find a particular species, maybe a Canyon Wren, Great Gray Owl, Northern Gannet, Yellow Wagtail, Whooping Crane, Henslow's Sparrow or Tufted Puffin.

The organization of the book is straightforward beginning with short sections entitled The Pian (the guide's coverage and how to find a given species), Helpful Suggestions (clothing, equipment, attracting birds and some sources of further information) and $A$ Code for using the Out-of-Doors (a list of common-sense but all too often forgotten do's and don'ts for the naturalist afield). These sections could have been enlarged to provide more useful information on nation-wide conservation programs and appropriate contacts of interest to the birdwatcher. For example, a listing of the main regional offices for Parks Canada, the Canadian Wildlife Service, the National Museums of Canada, the Nature Conservancy of Canada and Ducks Unlimited would help direct people to sites or provide them with current information on birds and access. Readers should also be cautioned that areas set aside for wildlife, be they sanctuaries, parks or wildlife areas, usually have some restrictions on access and public use to minimize disturbance to the wildlife and that the appropriate authority should be contacted before a visit.

The main part of the book (340 pages) consists of twelve chapters - one for each province and territory. At the beginning of each chapter is one key map showing locations of the major birding areas treated. These maps are clear and relatively error-free. Next is an overview highlighting bird specialties, ecological regions and provincial contacts. Then details are given for each birding area, including directions, accommodation, more contacts and of course the birds. A complete list of birds is not given for each area, rather each writer has chosen a mix of typical and rare species, indicating the best times of year to observe. Several "hot spots" are often described for one area (14 for the Dempster Highway, 16 
for Ottawa and 10 for Jasper National Park), improving the coverage and opening up many more options for the birder. The 40 pencil drawings of birds by Terry Thormin add a great deal to the reader's pleasure, however, they could be cross referenced to the text.

A list of birds for each province and territory is found in Appendix A. The information is for the most part up-to-date and fairly accurate with species status designated as "breeding", "present and usually migrant" or "vagrant, accidental or very few records". More categories are needed to avoid including too many species in the middle category when they are probably less frequent in occurrence (species like Townsend's Solitaire, Clark's Nutcracker, Whooping Crane for Manitoba). The status of cuckoos, phalaropes and swifts in Alberta is incorrect and Western Screech-Owl does not breed in Saskatchewan as indicated. These errors suggest that the reader should use this information with caution. Also, my copy of the guide was bound in such a way that some facing pages in Appendix A were offset slowing the task of comparing species status for several provinces. The second Appendix lists recent name changes affecting Canadian birds.

The guide is small enough $\left(5 \frac{1}{4} \times 8\right.$ inches and $1 \mathrm{lb} .2 \mathrm{oz}$.) to make it convenient to carry on a trip. The binding in my paper-back copy seems sturdy but the pages are only: glued-in not sewn-in, and may not stand the test of prolonged or rough use.

The guide provides a great deal of excellent information for the prairie birder planning trips across Canada. Did you know that Golden-winged Warblers are common in part of Riding Mountain National Park, or that July is the best summer month to see pelagic birds off Vancouver Island, or that daily boat tours can take you to a spectacular seabird colony of 100,000 birds including the world's largest Northern Gannet colony on
Bonaventure Island? There are enough contacts given for most places to get you started easily despite some incorrect telephone numbers (for Saskatchewan) and the inevitable telephone number and address changes which will occur. Birders coming to the prairies for a first visit or to see a prairie specialty (Trumpeter Swan, Whooping Crane, Sage Grouse) are also provided with sufficient information to plan their trip.

Two major weaknesses of this guide make it more difficult to use for the novice and experienced birder alike. First, there are no detailed maps of even the major birding areas - only Ottawa is afforded the honour. By rearranging the beginning of each chapter to include the key map and title on one page, perhaps one or two detailed area maps could have been included with no overall page increase. Such maps might reduce the text length and eliminate the need for comments like "drive west", and "head north on" which don't mean much if you are going the other way. Secondly, and most seriously, there is no index to the birds described in the text. And despite early encouragement in the guide to "look it up in the checklist, then turn to the text to determine how, when and where to find that or other species" you will more often than not read about the "other species." On well, that's how I found out that Goldenwinged Warblers breed in Riding Mountain.

The guide will do much to heighten our awareness of Canada's rich birdlife and strengthen our conviction that the best bird areas must receive adequate protection for the future. Cam Findlay and all the contributors are to be congratulated on producing a book of this high quality. Good birding to all those who use it.

I would like to thank Mary Gilliland for her assistance in checking the accuracy of the bird lists in Appendix A. Reviewed by Philip S. Taylor, 1714 Prince of Wales Avenue, Saskatoon, Saskatchewan. S7K 3E5 


\section{TWO IN THE BUSH}

ROSEMARY GAYMER. 1982. Illus. by E.B. SANDERS. 104 pp. $\$ 7.95$. (Available from the author through the Blue Jay Bookshop.)

People with abosorbing hobbies like to share them. In Two in the Bush, we are invited to enjoy what Rosemary Gaymer calls her "special sightings" in nature, particularly of birds. A keen bird watcher since she was a very little girl in England observing birds at a feeder inside her bedroom window, she writes here of her encounters and interactions with North American birds met since she came to Canada in 1955.

The author assures us that all the accounts are true and that most of the essays were woven around notes written in the field immediately after the observation. She has grouped her observations around a single species or family of birds, or a common theme such as flight. "Summer Jewels", for example, is the title of an essay on hummingbirds, and "Aerial Spectacular" describes the flight of the Turkey Vulture, Red-tailed Hawk, Common Snipe and Common Nighthawk. On a few occasions, a single memorable day's events are recorded, as in "Mass Encounter", which describes an unforgettable migration. At other times, an incident may be recorded simply for its folksy charm, as when a noisy field cricket upstages a platform speaker in a country hall. The essays follow the progression of the seasons.

A fine senstivity marks Rosemary Gaymer's observations, giving the reader the pleasure of a shared experience. Moreover, her observations include many points that casual birders miss. She has the serious bird student's interest in behaviour, and an eye for detail. Obviously, she is also a meticulous note taker, and she believes that "record-keeping is very much a part of the pleasure of bird watching." An aspect of bird behaviour that fascinates Ms. Gaymer and that I think she should explore further for a scientific paper is their game playing.

Two in the Bush was published by a small firm (Amethyst) now no longer in business. Its editorial staff seems to have been unable to give the advice usually offered authors, for there are stylistic weaknesses that would normally have been corrected in the manuscript. Redundancies, cliches, inexact allusions, mistakes in sentence structure are usually eliminated by a helpful literary editor, and an outside reader would surely have suggested deleting the information about distribution and physical characters available in any bird guide, and that only detracts from a personal account of encounters with birds and other wild creatures.

The book must now be obtained from the author; this can be done by ordering it through the Blue Jay Bookshop. Reviewed by Margaret Belcher, 2601 Winnipeg Street, Regina, Saskatchewan. S4P $1 \mathrm{H} 8$

\section{THE MARSHLAND WORLD}

RON WILSON and PAT LEE. 1982. Blandford Press, Dorset, England.

Hardcover. 152 pp., 114 photos. $\$ 22.95$.

This fifth book in a series of books on natural history and the environment published in England by Blandford Press deals with marshes, a habitat type largely overlooked by natural history authors and publishers. The previous books in the Blandford series encompass topics from waterfowl and wading birds of the world to the study of nocturnal wildlife.

The Marshland World is a comprehensive look at the wet environment; the 
topics range from what is a marsh, man and marshlands (crafts, eel-catching, water-fowling, marshland boats), marsh vegetation (aquatic and emergent plants, shrubs and trees), marshland animals (from invertebrates to fish through to mammals) to a consideration of the future of marshlands. Also Wilson and Lee provide an excellent comparison of freshwater and estuarine marshes while the common North American publications Pond Life (Golden Press) and Freshwater Marshes (University of Minnesota Press) focus almost exclusively on life within the freshwater system.

The uniqueness of this book lies in the section on crafts, the section dealing with reed husbandry, eel-catching and marshland boats. The cutting and harvesting of reed (Phragmites australis) for thatching is an important activity even today in British marshes. A variety of methods and tools for cutting and handling the reed are illustrated. The discussion of harvesting practices includes consideration of how frequent to crop and the influence of weather on the crop - questions with a familiar ring. The description of thatching is fascinating. This section includes comment on the quality and selection of material, the types of tools and the variation in technique in various areas of England. Other crafts included are basket making and reed weaving.

For eel-catching, the techniques described are similar to those employed by eel fishermen in Nova Scotia; good descriptions and photographs show what these are.

Prairie people have a great affinity for water, contrary to what might be expected, therefore many will find the history and use of marshland boats of great interest. Wilson and Lee described four boats specifically designed for marsh use.

The sections dealing with plant communities, individual plant species, the invertebrates, fish, amphibians, bird and mammals are detailed and informative. They are illustrated with excellent photographs. The only weakness I found in this book is the paucity of photographs of invertebrate life.

The Europeans share with us the problems of drainage and marsh manipulation for the perceived good of man rather than for the good of the marsh and its inhabitants. The solutions offered are few - the use of the Ramsar agreement, an international agreement for the protection of marsh areas nominated by a country. We of course have the Marsh Heritage program. What we need is a larger commitment by both urban and rural people to the conservation of these unique areas. Although this book is written about English marshlands, after reading it a North American would have the urge to visit a marsh.

It is a book which I will treasure in my library. - Reviewed by E.A. Driver, 22 Red River Road, Saskatoon, Saskatchewan. S7K $1 \mathrm{G} 3$

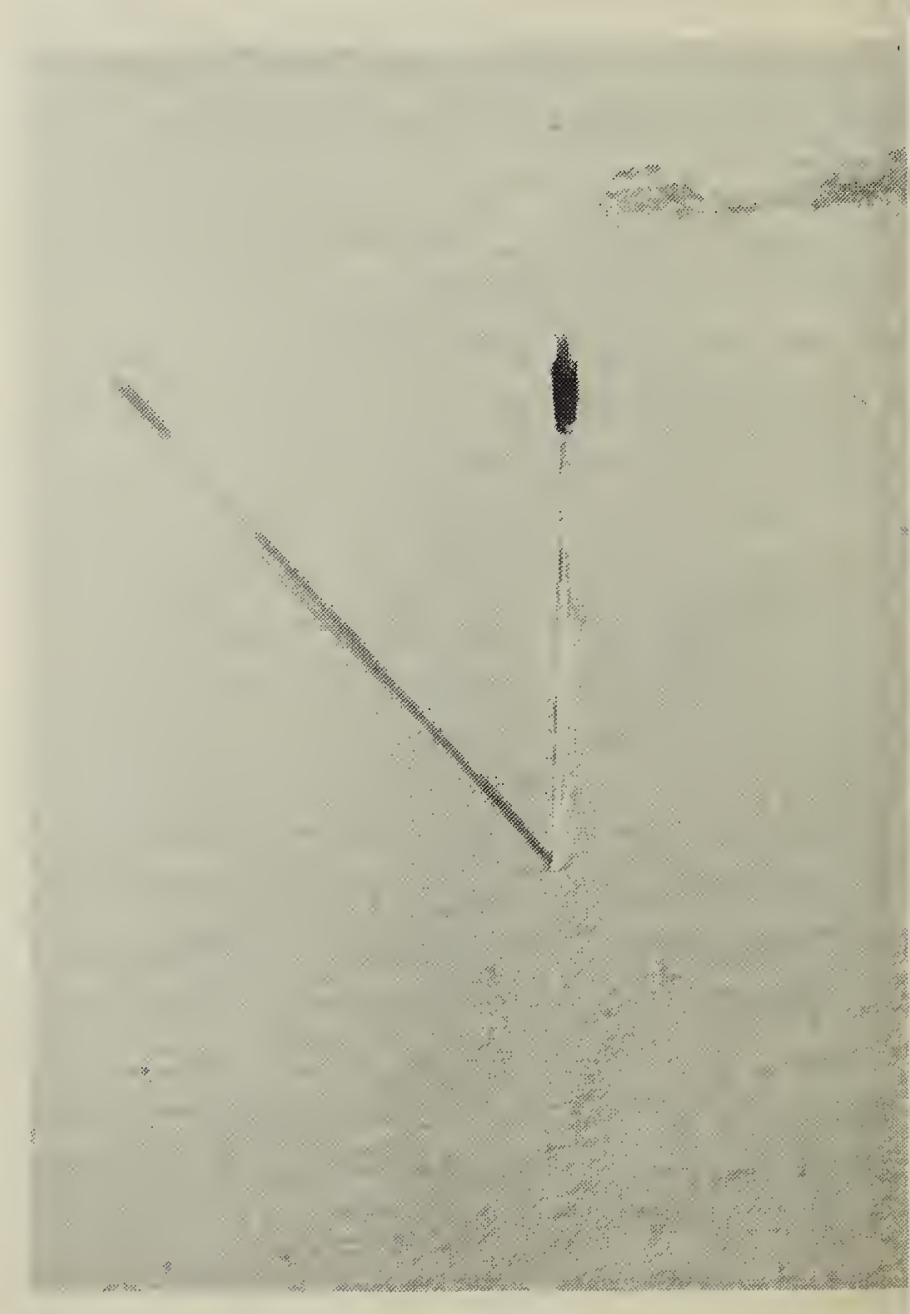

Winter Marsh

J.B. Gollop 